Original Research Article

\title{
A cross sectional study to assess knowledge, attitude and practice of rational antibiotic prescription among resident doctors
}

\author{
Anatte Antony*, Seema P. Mohamedali, Anuradha M.
}

Department of Pharmacology, Government Medical College, Kozhikode, Kerala, India

Received: 19 January 2019 Accepted: 27 February 2019

*Correspondence to:

Dr. Anatte Antony, Email: anattesept13@gmail.com

Copyright: (C) the author(s), publisher and licensee Medip Academy. This is an openaccess article distributed under the terms of the Creative Commons Attribution NonCommercial License, which permits unrestricted noncommercial use, distribution, and reproduction in any medium, provided the original work is properly cited.

\begin{abstract}
Background: Irrational prescription is a major contributor to the antimicrobial resistance. Resident doctors are the major focus of interventional programs aimed at rational prescription of antibiotics. So, their knowledge, attitude and practice regarding rational antibiotic prescription need to be assessed to plan future strategies.

Methods: A questionnaire based cross sectional study among interns and resident doctors of a Government Medical College was conducted. Questionnaire consisted of questions to assess knowledge, attitude and practice of resident doctors in rational antibiotic prescriptions and multiple-choice questions to assess practice of hospital antibiotic policy.

Results: 80 participants were enrolled in the study. All participants responded to yes or no questions and 47 answered multiple choice questions. $40 \%$ were aware of the current hospital antibiotic policy and $29 \%$ knew the term antibiotic stewardship. Only $15 \%$ were confident in their knowledge on antimicrobial resistance. $87.5 \%$ think there is no use in prescribing an antibiotic in common cold. $36.3 \%$ overprescribes antibiotics in their daily practice. Only $32.5 \%$ practiced de-escalation. $90 \%$ were educating patients regarding correct use of antibiotics. $90 \%$ send samples for culture and sensitivity but only $22.2 \%$ waited for results to start antibiotics.

Conclusions: There is a need for approaches that includes implementation of antibiotic policy and to plan for effective teaching programs regarding antibiotic resistance and importance of rational prescription of antibiotics which can improve the quality of antibiotic prescription and minimize antibiotic resistance.
\end{abstract}

Keywords: Antibiotic resistance, Antibiotic stewardship, Hospital antibiotic policy, Rational antibiotic prescription

\section{INTRODUCTION}

Rational prescription of antibiotics is defined as patients receiving appropriate antibiotic in right dose, and for right duration, with lowest cost to them and community. The irrational use of antibiotics has contributed to the growing problem of antibiotic resistance, which has become one of the most serious and growing threats to public health. ${ }^{1}$ The Center for Disease Control and Prevention (CDC) estimates more than two million people are infected with antibiotic-resistant organisms globally, resulting in approximately 23,000 deaths annually. ${ }^{2}$ The bacterial disease burden in India is among the highest in the world; consequently, antibiotics play a critical role in limiting morbidity and mortality in the country. This has led to increasing use of newer antibiotics and ultimately ended up with increased prevalence rates of multi-drug resistant bacteria. ${ }^{3}$ Various strategies have been proposed for rational use of antibiotics such as formulary restriction or replacement, antibiotic stewardship programs, feedback activities, prescription auditing, development of a hospital antibiotic policy based on local cumulative antibiogram 
etc. Antimicrobial stewardship has been defined as "the optimal selection, dosage, and duration of antimicrobial treatment that results in the best clinical outcome for the treatment or prevention of infection, with minimal toxicity to the patient and minimal impact on subsequent resistance". ${ }^{4}$ It is a hospital based multidisciplinary approach involving clinicians, infectious disease specialist, epidemiologist, microbiologist, pharmacologist, nurses, lab technicians etc.

The aim of development of a hospital antibiotic policy is to ensure rational prescription of antibiotics in the hospital to minimize the morbidity and mortality due to antimicrobial-resistant infection; and to preserve the effectiveness of antimicrobial agents in the treatment and prevention of communicable diseases. The antibiotic policy is essentially for prophylaxis, empirical and definitive therapy. It is developed based a local cumulative antibiogram. ${ }^{5}$ A good knowledge on rational antibiotic prescription and hospital antibiotic policy among resident doctors in a tertiary care hospital plays an important role in reducing antimicrobial resistance in a region. The purpose of this study was to assess the knowledge, attitude and practice of resident doctors about hospital antibiotic policy.

\section{METHODS}

This is a cross-sectional, questionnaire-based study conducted among the interns and resident doctors of various clinical departments of a Government medical college, in a period of two months. Sample size was 80 . Study group included interns, junior residents and senior residents and excluded doctors from non- clinical departments and those who fail to return filled forms within the stipulated time. After obtaining written informed consent and ensuring confidentiality, the participating doctor was given a questionnaire. The first section of the questionnaire involves the demographic data of the participant such as designation and department. The second section of the questionnaire involves questions to assess the knowledge of the participant about the hospital antibiotic policy and rational antibiotic usage. The third section of the questionnaire consists of questions to study the attitude of the participants towards the antibiotic policy and rational antibiotic use. The fourth section of the questionnaire consists of questions to evaluate the practice of antibiotic prescription. The fifth section consisted of multiple choice questions to assess knowledge and practice of current hospital antibiotic policy. After collecting back, the filled questionnaire, the data were entered in Microsoft excel worksheet. Analysis was done using frequency distribution and chi-square testing with the help of IBM-SPSS.

\section{RESULTS}

There were 80 participants enrolled in the study. The first four sections of questionnaire were answered by all participants. Only 47 participants responded to the multiple choice questions. Among the 80 participants, 59 were junior residents, 11 were interns and 10 were senior residents (Table 1).

\section{Table 1: Distribution of participants based} on departments.

\begin{tabular}{|ll|}
\hline Department & Percentage \\
\hline Dermatology & $24 \%$ \\
\hline Paediatrics & $23 \%$ \\
\hline General Medicine & $17 \%$ \\
\hline Pulmonary medicine & $8 \%$ \\
\hline ENT & $11 \%$ \\
\hline Orthopaedics & $11 \%$ \\
\hline Surgery & $6 \%$ \\
\hline
\end{tabular}

Table 2: Response to questions to assess knowledge on hospital antibiotic policy.

\begin{tabular}{|lll|}
\hline Question & Yes & No \\
\hline $\begin{array}{l}\text { Are you aware of the current hospital } \\
\text { antibiotic policy? }\end{array}$ & $40 \%$ & $60 \%$ \\
\hline $\begin{array}{l}\text { Have you gone through the antibiotic } \\
\text { policy of your department? }\end{array}$ & $32.5 \%$ & $67.5 \%$ \\
\hline $\begin{array}{l}\text { Do you think it meets all aspects } \\
\text { involved in prescription of } \\
\text { antimicrobials? }\end{array}$ & $15 \%$ & $85 \%$ \\
\hline
\end{tabular}

Table 3: Response to questions to assess knowledge on rational antibiotic prescription.

\begin{tabular}{|lcc|}
\hline Questions & Yes & No \\
\hline $\begin{array}{l}\text { Are you familiar with the term } \\
\text { antibiotic stewardship? }\end{array}$ & $29 \%$ & $71 \%$ \\
\hline $\begin{array}{l}\text { Do you feel confident about your } \\
\text { knowledge and practice in the area } \\
\text { of antimicrobial resistance? }\end{array}$ & $15 \%$ & $85 \%$ \\
\hline $\begin{array}{l}\text { Are you aware of antibiotic } \\
\text { escalation and de-escalation? }\end{array}$ & $61.3 \%$ & $38.7 \%$ \\
\hline $\begin{array}{l}\text { Do you think higher antibiotic } \\
\text { should be reserved and could be } \\
\text { used only after authorization from } \\
\text { senior physician? }\end{array}$ & $48.8 \%$ & $51.2 \%$ \\
\hline $\begin{array}{l}\text { Do you think there is advantage in } \\
\text { prescribing antibiotics in common } \\
\text { cold? }\end{array}$ & $12.5 \%$ & $87.5 \%$ \\
\hline $\begin{array}{l}\text { Do you prefer a broad spectrum } \\
\text { antibiotic as a first line option for } \\
\text { treatment of infections? }\end{array}$ & $67.5 \%$ & $32.5 \%$ \\
\hline
\end{tabular}

\section{Knowledge assessment}

\section{Knowledge on hospital antibiotic policy}

There were $40 \%$ of total study population were aware of the hospital antibiotic policy, and among those who were aware $71 \%$ read it, and among those who read, $39.13 \%$ 
think that it meets all aspects involved in the prescription of antimicrobials (Table 2).

\section{Knowledge on rational antibiotic prescription}

There were $29 \%$ of participants aware of the term antibiotic stewardship and $61.3 \%$ knew about deescalation of antibiotics. $15 \%$ were confident about their knowledge and practice in the field of antibiotic resistance. $87.5 \%$ knew that there is no advantage in prescribing antibiotic in common cold. $67.5 \%$ preferred a broad spectrum antibiotic as empirical therapy (Table 3).

\section{Attitude assessment}

There were $35 \%$ found that an antibiotic policy helped in reducing antibiotic resistance. $62.5 \%$ did not opt to consult a microbiologist before prescribing an antibiotic. $36.3 \%$ believed that they over prescribed antibiotics in their daily practice. $90 \%$ felt that under diagnosis and over diagnosis contributed to antibiotic resistance. $93.8 \%$ thought that over the counter use of antibiotics should be brought under control (Table 4).

Table 4: Response to questions to assess attitude.

\begin{tabular}{|lll|}
\hline Questions & Yes & No \\
\hline $\begin{array}{l}\text { Is hospital antibiotic policy helpful } \\
\text { in preventing antimicrobial } \\
\text { resistance? }\end{array}$ & $35 \%$ & $65 \%$ \\
\hline $\begin{array}{l}\text { Do you consult a microbiologist } \\
\text { before prescribing higher antibiotic? }\end{array}$ & $37.5 \%$ & $62.5 \%$ \\
\hline $\begin{array}{l}\text { Do you feel that you often over } \\
\text { prescribe antibiotics in your daily } \\
\text { practice? }\end{array}$ & $36.3 \%$ & $63.7 \%$ \\
\hline $\begin{array}{l}\text { Do you feel underdiagnosis } \\
\text { /overdiagnosis contributes to } \\
\text { inappropriate antibiotic use? }\end{array}$ & $90 \%$ & $10 \%$ \\
\hline $\begin{array}{l}\text { Do you think over the counter } \\
\text { dispensing of antibiotic should be } \\
\text { brought under control? }\end{array}$ & $93.8 \%$ & $6.2 \%$ \\
\hline
\end{tabular}

\section{Practice assessment}

The $21.3 \%$ of participants had a copy of hospital antibiotic policy and among those who had, only $47 \%$ referred it before prescribing an antibiotic. $62.5 \%$ consulted a senior faculty before prescribing an antibiotic. $32.5 \%$ practiced de-escalation. $90 \%$ of the participants practiced educating patients about correct use of antibiotics and discouraged over the counter buying of antibiotics. $90 \%$ send sample for culture and sensitivity, but only $22.2 \%$ waited for results before starting an antibiotic. $20 \%$ cross checked drug monograph about a new antibiotic (Table 5).

On analyzing the pattern of response among interns, junior residents and senior residents, it was found that knowledge of hospital antibiotic policy, knowledge about the term antibiotic stewardship and practice of de-escalation progressively increased during course duration and was more among senior residents. Confidence about practicing rational prescription of antibiotics was similar among interns and junior residents. The practice of proper hand washing technique was more among interns (Table 6).

Table 5: Responds to questions to assess practice.

\begin{tabular}{|lll|}
\hline Questions & Yes & No \\
\hline $\begin{array}{l}\text { Do you have a copy of hospital } \\
\text { antibiotic policy of your department? }\end{array}$ & $21.2 \%$ & $78.8 \%$ \\
\hline $\begin{array}{l}\text { If yes, do you refer it before } \\
\text { prescribing an antibiotic? }\end{array}$ & $47.1 \%$ & $52.9 \%$ \\
\hline $\begin{array}{l}\text { Do you consult your senior faculty } \\
\text { before starting a higher antibiotic? }\end{array}$ & $62.5 \%$ & $37.5 \%$ \\
\hline $\begin{array}{l}\text { Do you deescalate to lower antibiotic } \\
\text { if found sensitive? }\end{array}$ & $32.5 \%$ & $67.5 \%$ \\
\hline $\begin{array}{l}\text { Do you educate patients regarding } \\
\text { importance of using correct dosage } \\
\text { of antibiotic? }\end{array}$ & $88.8 \%$ & $11.2 \%$ \\
\hline $\begin{array}{l}\text { Do you educate patient regarding not } \\
\text { to use same prescription for similar } \\
\text { symptoms? }\end{array}$ & $82.5 \%$ & $17.5 \%$ \\
\hline $\begin{array}{l}\text { Do you discourage patient from } \\
\text { buying antibiotics over the counter? }\end{array}$ & $92.5 \%$ & $7.5 \%$ \\
\hline $\begin{array}{l}\text { Do you send sample for culture and } \\
\text { sensitivity in every relevant case } \\
\text { before starting antibiotic? }\end{array}$ & $90 \%$ & $10 \%$ \\
\hline $\begin{array}{l}\text { If yes, do you wait for culture and } \\
\text { sensitivity results to start an } \\
\text { antibiotic for patients in wards? }\end{array}$ & $22.2 \%$ & $77.8 \%$ \\
\hline $\begin{array}{l}\text { Does your choice of antibiotic } \\
\text { depends on availability of antibiotic } \\
\text { in your hospital? }\end{array}$ & $80 \%$ & $20 \%$ \\
\hline $\begin{array}{l}\text { Do you adhere to proper hand } \\
\text { washing techniques before consulting } \\
\text { each patients? }\end{array}$ & $51.2 \%$ & $48.8 \%$ \\
\hline $\begin{array}{l}\text { Do you properly adhere to proper } \\
\text { isolation techniques for infectious } \\
\text { diseases? }\end{array}$ & $76.2 \%$ & $23.8 \%$ \\
\hline $\begin{array}{l}\text { Does your duration of treatment with } \\
\text { antibiotics depend on clinical } \\
\text { improvement? }\end{array}$ & $75 \%$ & $25 \%$ \\
\hline $\begin{array}{l}\text { Do you cross check the statistical } \\
\text { data about the efficacy, safety and } \\
\text { spectrum of a newer antibiotic given } \\
\text { in a drug monograph? }\end{array}$ & $20 \%$ & $80 \%$ \\
\hline
\end{tabular}

Regarding the source of information about new antibiotics, half $(50 \%)$ of the study participants depended on teachers. $16 \%$ depended on journals, $6 \%$ on colleagues, $3 \%$ on pharmaceutical company representatives and $25 \%$ depended on all the four sources (Figure 1).

\section{Multiple choice questions}

Out of 80 participants, only 47 responded to the multiple choice questions. $40.4 \%$ preferred to wait for culture and sensitivity reports before starting an antibiotic for a case 
acute gastroenteritis. In a peadiatric case of an acute suppurative otitis media, only $10 \%$ waited for culture reports to start on antibiotics. $7 \%$ gave the correct choice of antibiotics for an elective hernioplasty. $15 \%$ waited for culture and sensitivity reports to start an antibiotic for chronic osteomyelitis (Table 7).

Table 6: Pattern of positive responses among interns, junior residents and senior residents to key questions.

\begin{tabular}{|lccc|}
\hline Key questions & Interns & $\begin{array}{l}\text { Junior } \\
\text { resident }\end{array}$ & $\begin{array}{l}\text { Senior } \\
\text { resident }\end{array}$ \\
\hline $\begin{array}{l}\text { Are u aware of } \\
\text { hospital antibiotic } \\
\text { policy? }\end{array}$ & $26.6 \%$ & $42.8 \%$ & $44.4 \%$ \\
\hline $\begin{array}{l}\text { Are you aware of the } \\
\text { term antibiotic } \\
\text { stewardship? }\end{array}$ & $20 \%$ & $25 \%$ & $77.7 \%$ \\
\hline $\begin{array}{l}\text { Are you confident } \\
\text { about your } \\
\text { knowledge and } \\
\text { practice in the area } \\
\text { of antimicrobial } \\
\text { resistance? }\end{array}$ & $13.3 \%$ & $11.86 \%$ & $33.3 \%$ \\
\hline $\begin{array}{l}\text { Do you deescalate to } \\
\text { lower antibiotic } \\
\text { when found } \\
\text { sensitive? }\end{array}$ & $33.3 \%$ & $28.5 \%$ & $55.5 \%$ \\
\hline $\begin{array}{l}\text { Do you adhere to } \\
\text { proper hand washing } \\
\text { techniques? }\end{array}$ & $80 \%$ & $44.6 \%$ & $44.4 \%$ \\
\hline
\end{tabular}

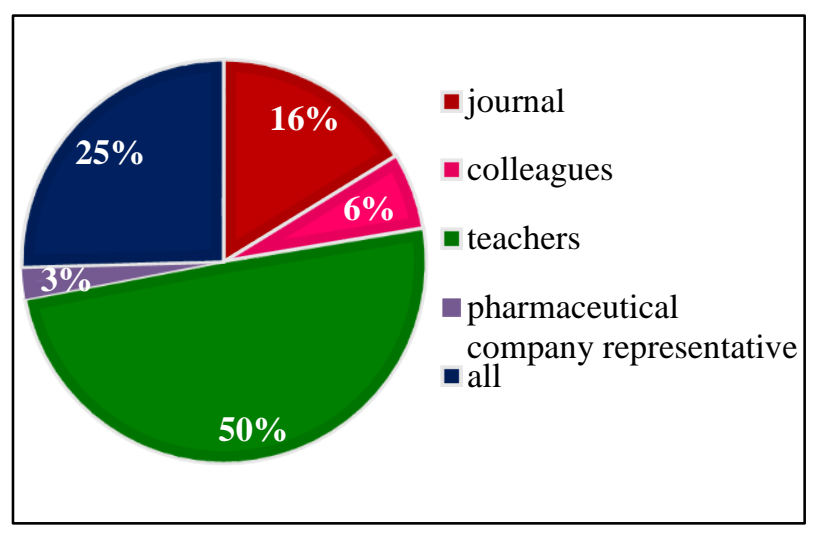

Figure 1: Source of information about new antibiotic.

\section{DISCUSSION}

The current study was concentrated to resident groups because they are the major prescribing section in a medical college, also modulations for implementing rational prescription of antibiotics should concentrate on these group. Thus, their knowledge, attitude and practice of rational antibiotic prescription has to be analyzed for implementing effective policies. Majority of the study population were junior residents from major medical specialties like general medicine, paediatrics and dermatology. Major concentration was given to these departments since majority of antibiotic prescription came from these departments.

Table 7: Response to multiple choice questions.

\begin{tabular}{|c|c|}
\hline Questions & $\begin{array}{l}\text { Correct } \\
\text { response }\end{array}$ \\
\hline $\begin{array}{l}\text { A case of acute gastroenteritis, with severe } \\
\text { dehydration was started on IV fluids and } \\
\text { inj. Ciprofloxacin IV } 200 \mathrm{mg} \mathrm{Q12H.}\end{array}$ & \multirow{5}{*}{$40.4 \%$} \\
\hline a) Choice of antibiotic is correct & \\
\hline b) Choice of antibiotic is wrong & \\
\hline $\begin{array}{l}\text { c) Wait for stool culture reports to start } \\
\text { antibiotic }\end{array}$ & \\
\hline $\begin{array}{l}\text { d) Send for blood and stool culture and } \\
\text { start antibiotic }\end{array}$ & \\
\hline $\begin{array}{l}\text { Culture report in the above case scenario } \\
\text { came as negative. What will you do next? }\end{array}$ & \multirow{5}{*}{$23.4 \%$} \\
\hline a) Stop antibiotic & \\
\hline b) Continue empirical therapy & \\
\hline c) Decision based on clinical judgement & \\
\hline d) Send for another culture & \\
\hline $\begin{array}{l}\text { A } 3 \text { year old child with acute suppurative } \\
\text { otitis media, on Sy.amoxicillin for } 5 \text { days. } \\
\text { On examination she was sick looking }\end{array}$ & \multirow{5}{*}{$10 \%$} \\
\hline $\begin{array}{l}\text { a) Change to syrup cefixime and send } \\
\text { home }\end{array}$ & \\
\hline $\begin{array}{l}\text { b) Admit and start on empirical parentral } \\
\text { antibiotics, then change once results on } \\
\text { culture and sensitivity comes }\end{array}$ & \\
\hline $\begin{array}{l}\text { c) Send ear swab and treat accordingly } \\
\text { with parenteral antibiotics }\end{array}$ & \\
\hline d) Continue syrup amoxicillin & \\
\hline $\begin{array}{l}\text { Antibiotic of choice for an elective } \\
\text { hernioplasty is - }\end{array}$ & \multirow{5}{*}{$7 \%$} \\
\hline $\begin{array}{l}\text { a) Inj. Cefotaxim } 1 \mathrm{gm} \mathrm{IV} \text { and continue } \\
\text { for 2-3 days }\end{array}$ & \\
\hline $\begin{array}{l}\text { b) Inj. Cefaperazone }+ \text { sulbactum } 1.4 \mathrm{gm} \\
\text { IV and } 2 \text { doses post operatively }\end{array}$ & \\
\hline $\begin{array}{l}\text { c) Inj.cefotaxim } 1 \text { gm IV and continue for } \\
2 \text { doses post operatively }\end{array}$ & \\
\hline $\begin{array}{l}\text { d) Inj. Cefuroxime } 1.5 \mathrm{gm} \mathrm{IV} \text { and } \\
\text { continue for } 2 \text { doses post operatively }\end{array}$ & \\
\hline $\begin{array}{l}\text { Antibiotic therapy for chronic } \\
\text { osteomyelitis is - }\end{array}$ & \multirow{5}{*}{$15 \%$} \\
\hline $\begin{array}{l}\text { a) Parenteral vancomycin and } \\
\text { piperacillin- tazobactam }\end{array}$ & \\
\hline b) Parenteral ceftriaxone + vancomycin & \\
\hline c) Parenteral ceftriaxone + oral linezolid & \\
\hline d) Wait for culture and sensitivity reports & \\
\hline
\end{tabular}
correct answers according to hospital antibiotic policy are given in bold letters

Less than half (40\%) of the study population was aware of the advantages of having a hospital antibiotic policy in the institution. Comparing to a previous similar study by Malavika Singh et al, $90 \%$ were aware of the advantages of hospital antibiotic policy. ${ }^{6}$ Awareness about the 
antibiotic stewardship and de-escalation of antibiotics were less among the interns, but it progressively increased during the course duration. Only $15 \%$ of the population were confident about their knowledge and practice in the field of antimicrobial resistance. In the previous study by Malavika Singh et al, $78.5 \%$ of the study population were confident in their knowledge and practice. $87.5 \%$ were aware that there is no advantage in giving antibiotics to viral conditions like common cold. Comparing with a previous similar study by Poonam Patel et al conducted in interns and first year post graduate students, where $92.26 \%$ preferred to prescribe an antibiotic in rhinitis with fever, shows that the current study population has a good knowledge that viral infections does not require an antibiotic. $^{7}$

On assessing the attitude, only $35 \%$ believed that hospital antibiotic policy (HAP) helps in reducing antimicrobial resistance, but in the study by Malavika Singh et al, 86.2\% thinks HAP is helpful. $63.7 \%$ of study population believes that they do not over prescribe antibiotics in their daily practice and in a study by Hrishikesh Kashyapa et al, among resident physicians, $88.46 \%$ consider they do not overprescribe antibiotics. ${ }^{8} 90 \%$ of study population thinks that over-diagnosis and under-diagnosis contributes to inappropriate antibiotic use and over the counter dispensing of antibiotic should be brought under control.

On assessing the practice, only $21.3 \%$ of study population had a copy of hospital antibiotic policy and among those who had, only $47.05 \%$ referred to it before prescribing an antibiotic. The residents practicing hospital antibiotic policy is found to be less compared to the previous study by Malavika Singh et al, where $87.5 \%$ of study population had the copy. Majority (62.5\%) consulted a senior faculty before prescribing an antibiotic, this is comparable to previous study data by Pallavi Kulkarni et al were $72 \%$ consulted seniors before prescribing an antibiotic. ${ }^{9}$ In this study $67.5 \%$ agreed using a broad spectrum antibiotic for empirical therapy, $61.3 \%$ were aware of de-escalation, but only $32.5 \%$ practiced de-escalation, when comparing with the similar study by Malavika Singh et al, were $75 \%$ practiced de-escalation, shows that there is a gap between knowledge and practice of this study population.

Around $90 \%$ of participants send samples for culture and sensitivity in relevant cases. But, among those who send, only $22.22 \%$ waited for the results before starting an antibiotic. Majority were interested in educating the patients regarding correct use of antibiotic, not to use the same prescription of antibiotic for similar illness without consulting a physician and not to buy antibiotic over the counter. For majority, their choice of antibiotic depended on availability in the hospital. More than half of the study population adhered to proper hand washing and isolation techniques to prevent cross infections. Only 20\% cross checked a drug monograph that gives information about new antibiotic. Regarding information about new antibiotic, majority depended on teachers.
There were 47 participants responded to the multiple choice questions. First question was on the need for starting an antibiotic in a well-controlled diabetic lady with acute gastroenteritis with severe dehydration. $60 \%$ preferred starting an antibiotic in this case. But according to HAP, it is advised to wait for stool culture report to start an antibiotic. The data is comparable with the previous study by Poonam Patel et al, were $44.19 \%$ preferred giving an antibiotic to acute gastroenteritis. Second question was if the culture report came as negative and what to do next. Only $23 \%$ considered stopping the antibiotic, if started before. According to WHO database on quantitative medicinal use in developing countries, 54\% of acute diarrhea cases were unnecessarily treated with antibiotics. $^{10}$

Third case scenario was a case of acute suppurative otitis media which was managed with amoxicillin and presented now with persisting symptoms. According to HAP, it was to be managed by sending of ear swab for culture and sensitivity and then start antibiotics accordingly. But only $10 \%$ gave the right answer. The unwillingness of residents to wait for culture and sensitivity reports may be attributed to the delay in receiving the reports. Fourth case scenario was a case of surgical prophylaxis for an elective hernioplasty. According to HAP, the surgical prophylaxis for an elective procedure is inj. cefuroxime $1.5 \mathrm{gm} \mathrm{IV}$ with induction and 2 doses post operatively. Only $7 \%$ gave the right answer. This might be due to the reason that, the choice of antibiotic by residents depended on the availability of antibiotic in the hospital. Fifth scenario was a case of an uncontrolled diabetic presenting with a chronic osteomyelitis. According to HAP the correct answer is to wait for culture and sensitivity reports but only $15 \%$ made correct answer.

According to the present study data the awareness about the HAP and antibiotic stewardship progressed as the course duration progressed i.e., around $20 \%$ among interns to $70 \%$ among senior residents. Thus, educational programs ensuring active participation of interns and junior residents which may be continuing medical education, group discussions, lectures, workshops, printed materials like antibiotic formularies or face to face contact programs like counselling can be done. Hands on training on hand washing techniques and isolation techniques to be conducted every year, may help to ensure adherence to these practices among junior doctors. HAP formulated by the infection control committee should be effectively communicated to the junior prescribers. A copy of policy should be made available to all prescribing physicians and it can be pasted in an accessible site in out-patient departments and wards of every department. Also, supervising and monitoring of the prescription and timely feedback with methods to improve prescription can be effective. Limited antibiotic procurement lists, and structured medication order forms are other ways of implementing HAP. Since the choice of antibiotic depend on the availability of antibiotics in the hospital for majority, the essential antibiotic availability should be 
ensured. Delayed culture and sensitivity reports are a major attributor for not waiting for results to start antibiotic. This can be minimized by use of automated blood culture systems or other latest technical advances like peptide nucleic acid technology, rapid polymerase chain reaction etc. where results are made available in an hour.

According to the current estimates, if antimicrobial resistance is not tackled effectively now it can result in a death every three seconds by 2050. Inappropriate antibiotic use is a major cause of antimicrobial resistance. WHO has initiated programs for curbing this situation by popularizing antibiotic stewardship programs (ASP). Developing a hospital antibiotic policy is an integral part of ASP. This is a global initiative as exemplified by antibiotic smart use which is a workable model for promoting the rational use of antibiotics in Thailand. ${ }^{11}$ The study results points that intense enforcement of antibiotic stewardship programs in the institution is the need of the hour.

Limitation of the study is that it is a cross sectional questionnaire based study, response of the participants may be biased. But it can open an insight into areas were further interventions are required. A further prospective study with large sample size, with inclusion of prescription auditing is a future possibility.

\section{CONCLUSION}

The upcoming clinicians, that is the residents and interns should be the major focus of strategies to promote rational antibiotic prescription. Various interventional strategies can be, targeted interventions to improve antibiotic use like educational programs ensuring active participation. Managerial strategies to ensure implementing of hospital antibiotic policies like routine antibiotic auditing and feedbacks and ensuring sufficient government expenditure and enforce regulations to ensure timely availability and sensitivity of investigational reports to aid clinicians in their antibiotic choice. The study concludes that there is a need for approaches that includes implementation of antibiotic policy and to plan for effective undergraduate teaching programs regarding antibiotic resistance and importance of rational prescription of antibiotics which can improve the quality of antibiotic prescription and thereby minimizing the antibiotic resistance.

\section{ACKNOWLEDGEMENTS}

Authors would like to thank all the participants of the study who cooperated with them in the study.

Funding: No funding sources Conflict of interest: None declared

Ethical approval: The study was approved by the Institutional Ethics Committee

\section{REFERENCES}

1. Huttner A, Harbarth S, Carlet J, Cosgrove S, Goossens $\mathrm{H}$, Holmes A, et al. Antimicrobial resistance: a global view from the 2013 World Healthcare-Associated Infections Forum. Antimicrobial resistance and infection control. $2013 \mathrm{Dec} ; 2(1): 31$.

2. Center for Disease Control and Prevention. Antibiotic resistance threats in the United States, Atlanta, GA: CDC; 2013. Available at: https://www.cdc.gov/drugresistance/pdf/ar-threats2013-508.pdf. Accessed on 7 February 2019.

3. Ghafur. The Chennai declaration Recommendations of A roadmap- to tackle the challenge of antimicrobial resistance - A joint meeting of medical societies of India. Ind $\mathbf{J}$ Cancer. October-December 2012;49(4):84-95.

4. Gerding, D.N. The search for good antimicrobial stewardship. Jt Comm J Qual Improv. 2001;27:403-4.

5. Cabana MD, Rand CS, Powe NR, Wu AW, Wilson $\mathrm{MH}$, Abboud PA, et al. Why don't physicians follow clinical practice guidelines?: A framework for improvement. JAMA. 1999 Oct 20;282(15):1458-65.

6. Singh M, Singh AK. Knowledge, Attitude, Practice Study on Awareness of Antibiotic Stewardship among Healthcare professionals in a Tertiary Care Hospital in Delhi, IJCMAS. 2017;8(7) 238-45.

7. Patel P, Shah J. A Survey on Knowledge and Attitude of Rational Use of Antibiotics on Predesigned Proforma among Interns and 1st year Postgraduate Students'. Int J Pharma Scienc Res. Aug 2016;7(8),350-5.

8. Kashyapa H, Jadhav RB. Knowledge, attitudes and practice survey on rational use of antibiotics among prescribers in a tertiary care hospital in Solapur. IJPRBS. 2016;5(6):134-43.

9. Kulkarni P, Kuruvilla A, Roy R, Ravi I. An evaluation of knowledge, attitude and practice of rational antibiotic usage and antibiotic resistance among interns in a teaching tertiary care hospital: A crosssectional questionnaire based study, Ind J Pharm Pharmacol. October-December 2017;4(4);192-7.

10. Holloway KA. Promoting the rational use of antibiotics. In Regional Health Forum. 2011;15(1):122-30.

11. Sumpradit N, Chongtrakul P, Anuwong K, Pumtong S, Kongsomboon K, Butdeemee P, et al. Antibiotics Smart Use: a workable model for promoting the rational use of medicines in Thailand. Bulletin of the World Health Organization. 2012;90:905-13.

Cite this article as: Anatte A, Mohamedali SP, Anuradha M. A cross sectional study to assess knowledge, attitude and practice of rational antibiotic prescription among resident doctors. Int J Basic Clin Pharmacol 2019;8:704-9. 